\title{
EFEITO DO DESLINTAMENTO QUÍMICO SOBRE A OCORRÊNCIA E DESENVOLVIMENTO DE Colletotrichum gossypii ASSOCIADO ÀS SEMENTES DE ALGODOEIRO*
}

\author{
LUIZ G. CHITARRA**, JOSÉ C. MACHADO, GILMA S. CHITARRA \& MARIA DAS GRAÇAS G. C. VIEIRA
}

Universidade Federal de Lavras, Cx. Postal 37, 37.200-000, Lavras, MG, fax (035) 3829-1100

(Aceito para publicação em 26/11/2001)

Autor para correspondência: Luiz G. Chitarra

CHITARRA, L.G., MACHADO, J.C., CHITARRA, G.S. \& VIEIRA, M.G.G.C. Efeito do deslintamento químico sobre a ocorrência e desenvolvimento de Colletotrichum gossypii associado às sementes de algodoeiro. Fitopatologia Brasileira 27:128-133. 2002.

\section{RESUMO}

A primeira fase do trabalho objetivou avaliar o efeito do tempo de deslintamento químico, 1:30 e 4:30 min, sobre o nível de infecção de Colletotrichum gossypii inoculado artificialmente em sementes de algodoeiro (Gossypium hirsutum). Sementes de algodoeiro com línter foram inoculadas com $C$. gossypii, mediante contato das mesmas com colônias do fungo em placas de Petri de 9 $\mathrm{cm}$ de diâmetro, por $30 \mathrm{~h}$. Os parâmetros avaliados foram a ocorrência de fungos e o poder germinativo das sementes. Na segunda fase, o objetivo foi avaliar a influência do exsudato de sementes de algodoeiro, em função do tempo da duração do deslintamento com ácido sulfúrico, considerando-se as frações de sedimentação de sementes e diferentes condições de envelhecimento artificial sobre o desenvolvimento de C. gossypii, em condições de laboratório. As sementes foram deslintadas quimicamente com ácido sulfúrico comercial concentrado pelos períodos de 1:30 e 4:30 min, separadas em frações de sedimentação em água e submetidas ao envelhecimento artificial por 0,72 e $96 \mathrm{~h}$. Os substratos foram obtidos a partir do exsudato resultante da embebição contendo os eletrólitos lixiviados das sementes. O desenvolvimento de C. gossypii na presença do exsudato das sementes foi avaliado em meio agarizado, através da medição do crescimento micelial e da esporulação do fungo. $\mathrm{O}$ deslintamento químico, pelo período de 1:30 min, propiciou aumento do percentual de ocorrência de C. gossypii em sementes nãodesinfestadas superficialmente, e o crescimento micelial e a esporulação do fungo foram favorecidos pelo substrato proveniente de sementes deslintadas por 4:30 e 1:30 min, respectivamente.

Palavras-chave adicionais: inoculação artificial, esporulação, crescimento micelial.

\section{ABSTRACT \\ Effects of chemical delinting on the level of occurrence and development of Colletotrichum gossypii associated with cotton seeds}

The present work was conducted in two phases. The first phase evaluated how the lenght of time of chemical delinting, 1:30 and 4:30 min, effected the level of infection by Colletotrichum gossypii on artificially inoculated cotton (Gossypium hirsutum) seeds. Non-delinted cotton seeds were artificially inoculated with C. gossypii by by contact with fungal colonies in Petri dishes for $30 \mathrm{~h}$. The parameters evaluated were quality of health and the germination ratio. The second phase aimed at evaluating the influence of cotton seed exudates on the development of $C$. gossypii in function of the chemical delinting time with sulphuric acid, considering the sedimentation fractions in water and artificial aging periods of 0,72 and $96 \mathrm{~h}$ in laboratory conditions.
The seeds were delinted with sulphuric acid for 1:30 and 4:30 min, separated into sedimentation fractions in water and submitted to artificial aging for 0,72 e $96 \mathrm{~h}$. The substracts were obtained from the exudates containing the electrolytes leaked from the cotton seeds. The development of C. gossypii in seed exudates was evaluated in agar medium, measuring the mycelial growth and sporulation of the fungus. The results showed that chemical delinting for 1:30 min provided an increase in the incidence of $C$. gossypii in seeds, without superficial disinfestation. The mycelial growth and sporulation of the fungus were favoured on the substracts containing exudates of delinted seeds for $4: 30$ and 1:30 min, respectively.

\section{INTRODUÇÃO}

Um dos principais fungos patogênicos associados às sementes de algodoeiro (Gossypium hirsutum L.) é o Colletotrichum gossypii Southworth, causador da antracnose, doença responsável por consideráveis perdas econômicas. $\mathrm{O}$

\footnotetext{
* Parte da Tese de Mestrado do primeiro autor. Universidade Federal de Lavras (1996)

***Bolsista da CAPES
}

C. gossypii pode ser disseminado por sementes contaminadas ou infestadas por e, dependendo das condições climáticas predisponentes, essas sementes poderão originar plântulas com sintomas de tombamento (Pizzinato, 1988), podendo ocorrer a morte das mesmas (Pizzinato, 1987).

O deslintamento químico é uma prática realizada visando melhorar o desempenho das sementes de algodoeiro. No entanto, as práticas de beneficiamento utilizadas podem provocar alterações nas estruturas protetoras das sementes 
Efeito do deslintamento químico sobre a ocorrência e desenvolvimento de...

aumentando os vazamentos de constituintes químicos (Carvalho \& Nakagawa, 2000) ou se constituindo via de acesso a microrganismos (Machado, 2000).

De uma maneira geral, o início da atividade biológica dos propágulos (esporos, estruturas de resistência ou hifas dormentes) dos fungos fitopatogênicos é estimulada por componentes do exsudato produzido pela planta hospedeira (Schroth \& Snyder, 1960; Agrios, 1978; Dhingra \& Sinclair, 1985). Entre espécies, como Rhizoctonia solani Kuehn (Agrios, 1978) e Sclerotinia sclerotiorum (Lib.) de Bary (Coley-Smith \& King, 1969), a capacidade infetiva dos propágulos é adquirida somente após a absorção de determinadas substâncias químicas, em geral, açúcares (Schroth \& Snyder, 1960; Redington \& Peterson, 1971) e aminoácidos (Schroth \& Snyder, 1960). Em outras situações o exsudato produzido pelo vegetal pode exercer ação inibitória ou mesmo deletéria a certos grupos de patógenos (Agrios, 1978; Dhingra \& Sinclair, 1985).

Considerando, portanto, esses aspectos, o presente trabalho foi realizado com o objetivo de verificar o efeito do deslintamento químico sobre o nível de infecção de C. gossypii inoculado artificialmente em sementes de algodoeiro, e avaliar a influência do exsudato das sementes sobre o desenvolvimento desse fungo "in vitro".

\section{MATERIAL E MÉTODOS}

Os experimentos foram conduzidos no Laboratório de Patologia de Sementes do Departamento de Fitopatologia da Universidade Federal de Lavras - Lavras, MG, no período de agosto a outubro de 1995 .

\section{Efeito do deslintamento químico no nível de ocorrência de Colletotrichum gossypii em sementes de algodoeiro artificialmente inoculadas}

Foram utilizadas sementes de algodoeiro, cultivar IAC20, da safra 1994/1995, oriundas da região de Capinópolis MG, e um isolado de C. gossypii obtido de sementes deslintadas que foram incubadas pelo emprego do "blotter test" (Brasil, 1992).

$\mathrm{O}$ isolado do patógeno foi multiplicado em meio de cultura BDA (batata-dextrose-ágar) contido em placas de Petri de $9 \mathrm{~cm}$ de diâmetro, por oito dias à temperatura de $21 \pm 2{ }^{\circ} \mathrm{C}$ em regime alternado de $12 \mathrm{~h}$ luz fluorescente branca $/ 12 \mathrm{~h}$ escuro.

As sementes com línter foram desinfestadas superficialmente com hipoclorito de sódio $1 \%$, lavadas em água destilada esterilizada por três vezes e postas a secar por aproximadamente $24 \mathrm{~h}$ à temperatura ambiente. Em seguida, as sementes ( 80 por placa) foram colocadas e mantidas durante $30 \mathrm{~h}$ sobre as colônias do fungo em crescimento ativo na superfície do meio de cultura, dispostas de maneira a constituir uma única camada. As sementes, retiradas das placas e postas a secar sobre papel toalha, à temperatura ambiente, por 24 h, foram submetidas ao deslintamento químico com ácido sulfúrico comercial concentrado (96-98\%) por períodos de
1:30 e 4:30 min, sendo lavadas em água corrente e postas a secar sobre papel toalha durante $24 \mathrm{~h}$.

As avaliações foram realizadas por meio dos testes de sanidade (método de incubação em papel de filtro) e teste de germinação, conforme Brasil (1992). Para o primeiro, foram utilizadas placas de Petri de $15 \mathrm{~cm}$ de diâmetro contendo três folhas de papel de filtro esterilizadas, umedecidas com água destilada contendo 5 ppm de 2,4 Diclorofenoxiacetato de sódio. Por amostra foram analisadas 400 sementes, sendo a metade desinfestada superficialmente com hipoclorito de sódio a $1 \%$ durante $5 \mathrm{~min}$. O teste foi realizado utilizando 25 sementes por placa em oito repetições, por tratamento. As sementes foram incubadas por um período de sete dias, a $21 \pm 2{ }^{\circ} \mathrm{C}$, sob regime alternado $12 \mathrm{~h}$ luz fluorescente branca/ $12 \mathrm{~h}$ escuro, sendo em seguida examinadas ao microscópio esteroscópio para determinação dos fungos a elas associados.

No teste de germinação, para cada tratamento foram usadas oito repetições de 25 sementes, semeadas em rolos de papel toalha, marca Germitest, umedecidos com água na proporção de 2,3:1 (duas vírgula três vezes o volume de água para uma parte do peso de papel); após a distribuição das sementes foram colocadas em germinador com temperatura regulada a $25{ }^{\circ} \mathrm{C}$, sendo a avaliação realizada no quarto dia após a instalação do teste.

O delineamento estatístico utilizado foi o inteiramente casualizado, com quatro tratamentos e oito repetições por tratamento, para efeito de análise de variância, e os resultados obtidos em percentagem, foram transformados por arc seno $\sqrt{\frac{x}{50}}$

Efeito do exsudato de sementes de algodoeiro sobre o desenvolvimento de Colletotrichum gossypii em substratos agarizados

Foram utilizados dois lotes de sementes de algodoeiro, variedade IAC-21, da safra 1993/94, produzidos nas regiões de Capinópolis, MG e Itumbiara, GO.

As sementes foram inicialmente homogeneizadas e submetidas ao deslintamento com ácido sulfúrico comercial concentrado (96-98\%), na proporção de $180 \mathrm{ml}$ de ácido para $1 \mathrm{Kg}$ de sementes, em dois períodos de exposição das sementes ao ácido sulfúrico: 1:30 e 4:30 min. Após estes períodos, as sementes foram lavadas em água corrente por $3 \mathrm{~min}$ e em seguida, colocadas em uma solução de bicarbonato de cálcio (1\%), durante $1 \mathrm{~min}$, lavadas novamente em água corrente por $30 \mathrm{~s}$ e postas a secar à sombra. As sementes foram homogeneizadas e divididas pelo método das divisões sucessivas (Brasil 1992). Parte das sementes foi colocada em um recipiente com água destilada, por $1 \mathrm{~min}$, com a finalidade de separar em duas classes de sedimentação: fração flutuante, com densidade menor que $1,00 \mathrm{~g} / \mathrm{cm}^{3}$, e fração sedimentada, com densidade maior que $1,00 \mathrm{~g} / \mathrm{cm}^{3}$. Posteriormente foram secadas à sombra até a umidade de aproximadamente $12 \%$, colocadas em sacos de papel Kraft e armazenadas em câmara seca e fria $\left(12{ }^{\circ} \mathrm{C}, 45 \%\right.$ umidade 
relativa). Os tratamentos definidos, portanto, foram dois tempos de deslintamento (1:30 e 4:30 min), três frações de sedimentação [não-fracionada (integral), fração flutuante e fração sedimentada], e três períodos de envelhecimento artificial (zero, 72 e $96 \mathrm{~h}$ ), totalizando 18 tratamentos + três testemunhas (não-deslintadas e envelhecidas artificialmente nos tempos acima referidos).

$\mathrm{O}$ envelhecimento artificial foi realizado utilizando caixas plásticas "gerbox" com compartimento individual (minicâmaras adaptadas), possuindo, no seu interior, uma bandeja de tela de alumínio, onde foram distribuídas as sementes (Handbook of Vigour Test Methods, ISTA 1995). As caixas "gerbox" foram acondicionadas em câmara BOD e mantidas por um período de $72 \mathrm{~h}$ e $96 \mathrm{~h}$, a uma temperatura de $42 \pm 1{ }^{\circ} \mathrm{C}$ e $100 \%$ de umidade relativa.

Para obtenção dos exsudatos, foram tomadas duas subamostras de 650 sementes, as quais foram colocadas em dois copos plásticos de $500 \mathrm{ml}$ contendo, cada um, $180 \mathrm{ml}$ de água deionizada. Os copos contendo as sub-amostras foram mantidos à temperatura ambiente por $24 \mathrm{~h}$, sendo, após este período, removida as sementes e efetuado o recolhimento do exsudato, coado em gaze.

Os substratos foram preparados com a seguinte composição: $20 \mathrm{~g}$ de dextrose mais $20 \mathrm{~g}$ de ágar mais o exsudato das sementes provenientes dos diversos tratamentos completando-se com água destilada - volume de $1000 \mathrm{ml}$. Foi determinado o $\mathrm{pH}$ com o auxílio de um peagâmetro (micronal, pH-metro, B371). Posteriormente os substratos foram submetidos à autoclavagem à $121^{\circ} \mathrm{C}$ por $20 \mathrm{~min}$. Para cada tratamento foram preparadas quatro placas de Petri de $9 \mathrm{~cm}$ de diâmetro, cada uma recebendo $15 \mathrm{ml}$ de substrato. Após a solidificação do meio, foi colocado ao centro da placa, sobre o substrato, um disco de ágar com o micélio do fungo retirado da periferia da colônia, de cultura de sete dias de idade, desenvolvida em condições de incubação discutidas anteriormente.

Durante o desenvolvimento do fungo foram realizadas, a cada 48 h, medições dos diâmetros das colônias em posições ortogonais entre si, na face inferior das placas, até o décimo dia, quando a área $\left(\pi r^{2}\right)$ da colônia foi calculada. A taxa de crescimento micelial foi expressa em $\mathrm{mm} / 24 \mathrm{~h}$ de incubação.

O delineamento utilizado foi inteiramente ao acaso em esquema fatorial 14 (substratos) versus três (tempos de envelhecimento artificial - 0,72 e $96 \mathrm{~h}$ ), totalizando 84 tratamentos, com quatro repetições por tratamento.

Para avaliação do número de esporos foram preparadas suspensões através da adição de $10 \mathrm{ml}$ de água destilada e 50 ppm de Tween 80 em cada placa de Petri contendo a colônia fúngica. Com o auxílio de um pincel fino, foi feita a raspagem superficial em cada colônia, obtendo a liberação dos esporos. A contagem do número de esporos foi feita com o auxílio da câmara de Neubauer em microscópio óptico e os resultados foram expressos em $\mathrm{n}^{\mathrm{o}}$ de esporos $/ \mathrm{cm}^{2}$. A análise estatística foi realizada transformando os dados para $\sqrt{\mathrm{x}+0.5}$

\section{RESULTADOS E DISCUSSÃO}

Efeito do deslintamento químico sobre a incidência de fungos em sementes de algodoeiro inoculadas artificialmente com Colletotrichum gossypii

Para todos os tratamentos, igualmente ao verificado por Teixeira (1995), as maiores incidências de fungos ocorreram em sementes sem desinfestação superficial (Tabela 1). A maior incidência do C. gossypii ocorreu nas sementes inoculadas, sem desinfestação superficial, deslintadas por 1:30 min; e as menores incidências verificaram-se nas sementes não inoculadas. Quando se considerou o deslintamento químico, para sementes não-desinfestadas, observou-se maior incidência de C. gossypii nas sementes deslintadas por 1:30 min. Sementes deslintadas por 4:30 min não apresentaram diferenças quanto a incidência desse organismo em relação as sementes inoculadas não-deslintadas. Pode ser observado no entanto, que para Fusarium sp., houve uma redução na incidência deste organismo com o deslintamento com ácido sulfúrico e, Penicillium sp. apresentou tendência de aumento de incidência com o aumento do tempo de deslintamento. Estes resultados de certa forma vão ao encontro aos resultados de Sherbarkoff (1927) citado por Brown (1933), o qual afirma que o deslintamento químico com ácido sulfúrico elimina as bactérias e fungos da superfície das sementes. Os resultados evidenciam que o deslintamento químico faz com que as incidências dos fungos associados às sementes sejam variáveis possivelmente em função da posição do inóculo nas sementes e o tempo de exposição a esse tratamento.

Quanto à germinação, houve diferenças estatisticamente significativas entre os tratamentos (Tabela 2). As sementes inoculadas com C. gossypii, deslintadas ou não, apresentaram uma porcentagem de germinação significativamente menor em relação às sementes com línter e nãoinoculadas. Apesar do deslintamento químico por um período de 4:30 min não ter alterado o nível de ocorrência do referido fungo (Tabela 1), a porcentagem de germinação (Tabela 2) foi menor, provavelmente em função dos danos que este tipo de tratamento possa ter provocado às sementes. Observa-se ainda (Tabela 1), que, apesar de não haver diferenças estatísticas nas incidências de Penicillium sp. e de Aspergillus sp., entre as sementes deslintadas e sementes nãodeslintadas, os valores obtidos para os aumentos na incidência destes fungos foram mais elevados naqueles que sofreram o processo de deslintamento, o que deve ter contribuido para a deterioração das mesmas. Lima et al. (1984) verificaram o decréscimo no vigor e na porcentagem de germinação de sementes de algodoeiro inoculadas com fungos Aspergillus flavus, Aspergillus niger e Rhizopus sp., quando comparadas com sementes não-inoculadas. Segundo Sobreira (1988), o línter que reveste as sementes de algodoeiro facilita a presença de microrganismos, principalmente fungos. O deslintamento químico com ácido sulfúrico tem alto poder desinfestante (McDonald et al., 1947), e, conseqüentemente, proporciona maior percentual de germinação do que as sementes deslintadas mecanicamente (Kanawabe \& 
Efeito do deslintamento químico sobre a ocorrência e desenvolvimento de...

TABELA 1 - Incidência (\%) de fungos em sementes de algodoeiro (Gossypium hirsutum), inoculadas artificialmente com Colletotrichum gossypii e deslintadas com ácido sulfúrico. UFLA LAVRAS-MG, 1995

\begin{tabular}{|c|c|c|c|c|c|c|}
\hline \multirow{2}{*}{$\begin{array}{l}\text { Sementes } \\
\text { Deslintadas } \\
\text { e Inoculadas }\end{array}$} & \multicolumn{6}{|c|}{ Patógenos } \\
\hline & $\begin{array}{c}\text { Colletotrichum } \\
\text { gossypii }\end{array}$ & Fusarium sp. & $\begin{array}{c}\text { Lasiodiplodia } \\
\text { theobromae }\end{array}$ & Rhizopus sp. & Aspergillus sp. & Penicillium sp. \\
\hline $0 \min ^{1}$ & & & & & & \\
\hline $\mathrm{D}^{2}$ & $49,0 \mathrm{c}$ & $40,5 \mathrm{ab}$ & $0,5 \mathrm{a}$ & $1,0 \mathrm{a}$ & $12,0 \mathrm{a}$ & $11,5 \mathrm{a}$ \\
\hline ND & $83,0 \mathrm{~b}$ & $47,0 \mathrm{a}$ & $1,5 \mathrm{a}$ & $0,5 \mathrm{a}$ & $8,0 \mathrm{ab}$ & $8,5 \mathrm{ab}$ \\
\hline \multicolumn{7}{|l|}{$1: 30 \mathrm{~min}$} \\
\hline $\mathrm{D}$ & $38,5 \mathrm{c}$ & $14,5 \mathrm{c}$ & $2,5 \mathrm{a}$ & $0,0 \mathrm{a}$ & $12,0 \mathrm{ab}$ & $4,5 \mathrm{c}$ \\
\hline ND & $98,0 \mathrm{a}$ & $16,0 \mathrm{c}$ & $2,5 \mathrm{a}$ & $0,0 \mathrm{a}$ & $22,0 \mathrm{a}$ & $5,5 \mathrm{abc}$ \\
\hline \multicolumn{7}{|l|}{$4: 30 \mathrm{~min}$} \\
\hline $\mathrm{D}$ & $36,0 \mathrm{c}$ & $16,5 \mathrm{c}$ & $2,5 \mathrm{a}$ & $0,0 \mathrm{a}$ & $8,5 \mathrm{ab}$ & $8,0 \mathrm{abc}$ \\
\hline ND & $81,5 \mathrm{~b}$ & $22,5 \mathrm{c}$ & $2,5 \mathrm{a}$ & $0,0 \mathrm{a}$ & $5,0 \mathrm{~b}$ & $14,0 \mathrm{a}$ \\
\hline \multicolumn{7}{|c|}{ Sementes não-deslintadas e não-inoculadas } \\
\hline $\mathrm{D}$ & $7,0 \mathrm{~d}$ & $14,5 \mathrm{c}$ & $0,0 \mathrm{a}$ & $0,0 \mathrm{a}$ & $3,5 \mathrm{~b}$ & $1,5 \mathrm{c}$ \\
\hline ND & $10,0 \mathrm{~d}$ & $24,0 \mathrm{bc}$ & $0,5 \mathrm{a}$ & $0,0 \mathrm{a}$ & $3,5 \mathrm{~b}$ & $2,0 \mathrm{bc}$ \\
\hline
\end{tabular}

${ }^{1}$ Duração do deslintamento.

${ }^{2} \mathrm{D}=$ sementes desinfestadas com hipocloreto de sódio $1 \%, \mathrm{ND}=$ sementes não desinfestadas.

CV $(\%) 17,8$.

Médias seguidas pela mesma letra nas linhas não diferem entre si pelo teste de Tukey ao nível de 5\% de probabilidade.

Kashyarde, 1983; Paolinelli et al., 1995). Também para o presente trabalho, o estágio de deterioração natural das sementes anterior ao tratamento químico pode ter influenciado sobremaneira na qualidade dessas (germinação inicial igual a 59\%), provavelmente as predispuseram a um efeito negativo do tratamento, resultando em aumento na incidência dos fungos Penicillium sp. e Aspergillus sp.

Efeito do exsudato de sementes de algodoeiro sobre o desenvolvimento de Colletotrichum gossypii em substratos agarizados

Os valores médios de $\mathrm{pH}$ dos exsudatos de sementes de algodoeiro submetidas a diversos tratamentos, variaram de 4,0 a 5,0, de 5,0 a 6,0 e 7,0 para sementes deslintadas por 1:30, 4:30 min e não deslintadas respectivamente.

O crescimento de $C$. gossypii foi mais acentuado em substratos contendo exsudato de sementes deslintadas (Tabela 3). Para sementes não envelhecidas $(0 \mathrm{~h})$, os substratos provenientes das sementes deslintadas, da fração sedimentada, proporcionaram maiores taxas de crescimento micelial de $C$. gossypii, independente do tempo de exposição das sementes ao ácido sulfúrico. $\mathrm{O} \mathrm{pH}$ do exudato $(7,2)$ e, provavelmente, a menor lixiviação de eletrólitos nas sementes não deslintadas podem ter afetado, negativamente, o desenvolvimento do fungo. No processo de embebição das sementes, os íons Ca, $\mathrm{Mg}, \mathrm{Mn}, \mathrm{K}$, e $\mathrm{Cl}$ são lixiviados, ocasionando a elevação do $\mathrm{pH}$ do exsudato da semente. Em sementes deterioradas verifica-se maior lixiviação destes íons, porém lixiviam maior quantidade de $\mathrm{H}^{+}$, ocasionando um menor $\mathrm{pH}$ nos seus exsudatos (Loomis \& Smith, 1980).

Durante o processo de envelhecimento das sementes, ocorre a perda da integridade das membranas celulares, resultando na exsudação de determinados íons como $\mathrm{K}^{+}, \mathrm{Ca}^{+2}$, $\mathrm{Mn}^{+2}$ e $\mathrm{Mg}^{+2}$, certos açúcares, aminoácidos, enzimas e sais durante o processo de embebição (Woodstock, 1988). Outros fatores podem afetar a exsudação, como, por exemplo, o grau de deterioração (Ching, 1972), incidência de danos causada pela velocidade de embebição (Powell, 1986), ocorrência de injúrias no tegumento das sementes (Loefler, 1981), e temperatura e tempo de embebição (Loefler et al.,1988). No presente estudo, provavelmente a ação do ácido sulfúrico, por um período mais longo, favoreceu o rompimento das ligações glicosídicas e, conseqüentemente, propiciou maior lixiviamento de solutos citoplasmáticos enriquecendo o substrato. $\mathrm{O}$ pH entre 5,0 e 6,0 destes exsudatos, também pode ter favorecido o desenvolvimento de $C$. gossypii.

Em relação ao crescimento micelial de $C$. gossypii em substrato agarizado contendo A.D.A. (exsudato de sementes de algodoeiro-dextrose-ágar) diluído, pôde-se observar que não houve diferença entre os tratamentos.

Os resultados (Tabela 4) indicam uma tendência de maior produção de conídios por $C$. gossypii em substratos não diluídos, provenientes de sementes não deslintadas e

TABELA 2 - Germinação(\%) de sementes de algodoeiro (Gossypium hirsutum) deslintadas com ácido sulfúrico e inoculadas artificialmente com Colletotrichum gossypii. UFLA - Lavras MG, 1995

\begin{tabular}{lc}
\hline \hline Tratamento & (\%) germinação \\
\hline Sementes com línter não-inoculadas & $59 \mathrm{a}$ \\
Sementes com línter inoculadas & $29 \mathrm{~b}$ \\
$\begin{array}{l}\text { Sementes deslintadas por 1:30 min e } \\
\text { inoculadas }\end{array}$ & $19 \mathrm{bc}$ \\
$\begin{array}{l}\text { Sementes deslintadas por 4:30 min e } \\
\text { inoculadas }\end{array}$ & $14 \mathrm{c}$ \\
\hline
\end{tabular}

Médias seguidas pela mesma letra na coluna não diferem entre si pelo teste de Tukey ao nível de $5 \%$ de probabilidade. 


\section{L.G. Chitarra et al.}

TABELA 3 - Taxas de crescimento micelial $(\mathrm{mm} / 24 \mathrm{~h})$ em diferentes períodos de desenvolvimento de Colletotrichum gossypii em substratos agarizados contendo exsudato de sementes de algodoeiro (Gossypium hirsutum), deslintadas com ácido sulfúrico, separadas por diferentes frações de sedimentação e envelhecidas artificialmente. UFLA-Lavras, MG, 1995

\begin{tabular}{|c|c|c|c|}
\hline \multirow[t]{2}{*}{ Tratamento } & \multicolumn{3}{|c|}{$\begin{array}{c}\text { Duração do período de envelhecimento precoce } \\
\text { (h/crescimento micelial) }\end{array}$} \\
\hline & $\mathbf{0}$ & 72 & 96 \\
\hline \multicolumn{4}{|c|}{ SUBSTRATO NÃO DILUÍDO } \\
\hline Sementes com línter & $11,39 \mathrm{~b}$ & $11,21 \mathrm{~b}$ & $11,82 \mathrm{bc}$ \\
\hline Sementes nãofracionadas, deslintadas por 1:30 min & $12,36 \mathrm{ab}$ & $11,69 \mathrm{~b}$ & $12,90 \mathrm{abc}$ \\
\hline Sementes da fração flutuante, deslintadas por 1:30 min & $12,38 \mathrm{ab}$ & $11,87 \mathrm{~b}$ & $11,34 \mathrm{c}$ \\
\hline Sementes da fração sedimentada, deslintadas por 1:30 min & $13,13 \mathrm{a}$ & $11,82 \mathrm{~b}$ & $13,37 \mathrm{ab}$ \\
\hline Sementes não-fracionadas, deslintadas por $4: 30 \mathrm{~min}$ & $12,49 \mathrm{ab}$ & $13,48 \mathrm{a}$ & $14,07 \mathrm{a}$ \\
\hline Sementes da fração flutuante, deslintadas por 4:30 min & $12,47 \mathrm{ab}$ & $12,24 \mathrm{ab}$ & $12,18 \mathrm{bc}$ \\
\hline Sementes da fraçãosedimentada, deslintadas por 4:30 min & $12,95 \mathrm{a}$ & $11,53 \mathrm{~b}$ & $12,99 \mathrm{abc}$ \\
\hline Médias & 12,49 & 11,98 & 12,66 \\
\hline CV $(\%)$ & 8,84 & 8,27 & 9,04 \\
\hline \multicolumn{4}{|c|}{ SUBSTRATO DILUÍDO } \\
\hline Sementes com línter & $7,94 \mathrm{a}$ & $8,58 \mathrm{a}$ & $9,37 \mathrm{a}$ \\
\hline Sementes nãofracionadas, deslintadas por 1:30 min & $8,64 \mathrm{a}$ & $9,12 \mathrm{a}$ & $9,25 \mathrm{a}$ \\
\hline Sementes da fração flutuante, deslintadas por 1:30 min & 8,88 a & $8,60 \mathrm{a}$ & $9,53 \mathrm{a}$ \\
\hline Sementes da fração sedimentada, deslintadas por 1:30 min & $8,23 \mathrm{a}$ & $8,52 \mathrm{a}$ & $9,20 \mathrm{a}$ \\
\hline Sementes nãofracionadas, deslintadas por 4:30 min & $8,40 \mathrm{a}$ & $8,64 \mathrm{a}$ & $9,50 \mathrm{a}$ \\
\hline Sementes da fração flutuante, હslintadas por 4:30 min & $8,22 \mathrm{a}$ & $8,91 \mathrm{a}$ & $9,54 \mathrm{a}$ \\
\hline Sementes da fração sedimentada, deslintadas por 4:30 min & $8,02 \mathrm{a}$ & $8,55 \mathrm{a}$ & $9,35 \mathrm{a}$ \\
\hline Médias & 8,33 & 8,70 & 9,39 \\
\hline CV $(\%)$ & 9,96 & 10,51 & 5,58 \\
\hline
\end{tabular}

Médias seguidas pela mesma letra nas colunas não diferem entre si pelo teste de Tukey ao nível de 5\% de probabilidade.

deslintadas por 1:30 (sementes não fracionadas), sem envelhecimento precoce. A exceção de sementes com línter, houve uma tendência de maior produção de conídios para exsudatos de sementes envelhecidas por $96 \mathrm{~h}$.

A esporulação de $C$. gossypii em substrato agarizado diluído, não apresentou diferença estatística entre os tratamentos. Houve tendência de uma maior esporulação em substrato contendo exsudato provenientes de sementes deslintadas por 1:30 min, fração flutuante não envelhecida. Para sementes envelhecidas por 72 e 96 h, o deslintamento

TABELA 4 - Esporulação ( $\mathrm{n}^{0}$ de conídios $\times 10^{5} / \mathrm{cm}^{2}$ de colônia) de Colletotrichum gossypii em substratos agarizados contendo exsudato de sementes de algodoeiro (Gossypium hirsutum), deslintadas com ácido sulfúrico, separadas por diferentes frações de sedimentação e envelhecidas artificialmente. UFLA-Lavras, MG, 1995

\begin{tabular}{|c|c|c|c|}
\hline \multirow[t]{2}{*}{ Tratamento } & \multicolumn{3}{|c|}{$\begin{array}{c}\text { Duração do período de envelhecimento precoce } \\
\text { (h/crescimento micelial) }\end{array}$} \\
\hline & $\mathbf{0}$ & 72 & 96 \\
\hline \multicolumn{4}{|c|}{ SUBSTRATO NÃO DILUÍDO } \\
\hline Sementes nãofracionadas, deslintadas por 1:30 min & $15,33 \mathrm{a}$ & $11,51 \mathrm{ab}$ & $21,00 \mathrm{ab}$ \\
\hline Sementes da fração flutuante, deslintadas por 1:30 min & $6,23 \mathrm{~b}$ & $7,81 \mathrm{ab}$ & $26,59 \mathrm{a}$ \\
\hline Sementes da fração sedimentada, deslintadas por 1:30 min & $5,62 \mathrm{~b}$ & $4,10 \mathrm{~b}$ & $11,83 \mathrm{bc}$ \\
\hline Sementes da fração sedimentada, deslintadas por 4:30 min & $4,46 \mathrm{~b}$ & $5,46 \mathrm{~b}$ & $12,91 \mathrm{bc}$ \\
\hline Médias & 7,89 & 8,46 & 14,76 \\
\hline CV $(\%)$ & 19,78 & 17,81 & $\mathbf{1 0 , 8 0}$ \\
\hline \multicolumn{4}{|c|}{ SUBSTRATO DILUÍDO } \\
\hline Sementes com línter & $0,67 \mathrm{ab}$ & $0,77 \mathrm{ab}$ & $0,34 \mathrm{c}$ \\
\hline Sementes da fração flutuante, deslintadas por 4:30 min & $0,58 \mathrm{ab}$ & $1,08 \mathrm{a}$ & $1,69 \mathrm{a}$ \\
\hline Sementes da fração sedimentada, desihtadas por 4:30 min & $0,33 \mathrm{~b}$ & $0,87 \mathrm{ab}$ & $0,65 \mathrm{bc}$ \\
\hline Médias & 0,66 & 0,76 & 1,14 \\
\hline CV $(\%)$ & 14,91 & 13,36 & 10,52 \\
\hline
\end{tabular}

Médias seguidas pela mesma letra nas colunas não diferem entre si pelo teste de Tukey ao nível de 5\% de probabilidade. 
Efeito do deslintamento químico sobre a ocorrência e desenvolvimento de...

por 1:30, classe de sementes não fracionadas e deslintamento por 4:30, classe de sementes fração flutuante, propiciaram tendência de maior esporulação.

\section{REFERÊNCIAS BIBLIOGRÁFICAS}

AGRIOS, G.N. Plant Pathology $2^{\text {nd }}$ ed. New York; Academic Press. 1978.

BRASIL. Ministério da Agricultura e da Reforma Agrária. Regras para Análise de Semente. Brasília. AGIPLAN. 1992.

BROWN, A.H. Effects of sulphuric acid delinting on cotton seeds. Botanical Gazette 94:755-770. 1933.

CARVALHO, N.M \& NAKAGAWA, J. Sementes: ciência, tecnologia e produção. 4 ed. Jaboticabal. FUNEP. 2000.

CHING, T.M. Aging stress on physiological and biochemical activities of crimson clover (Trifolium incarnatum L. var Dixie) seeds. Crop Science 12:415-418. 1972.

COLEY SMITH, J.R. \& KING, J.E. The production by species of Allium of alkyl sulphides and their effect on germination of sclerotia of Sclerotium cepivorum Berk. Annual Applied Biological 64:289-301. 1969.

DHINGRA, O.D. \& SINCLAIR, J.B. Basic Plant Pathology Methods. Boca Raton. CRC Press. 1985.

INTERNATIONAL SEED TESTING ASSOCIATION - ISTA. Handbook of vigour test methods. $3^{\text {rd }}$ ed. Zurich. 1995.

KANAWABE, L.R. \& KASHYARDE, M.M. Effects of delinting and size on germination of cotton seed. Journal of Maharastra Agricultural Universities 8:262-264. 1983.

LIMA, E.F., VIEIRA, R.M., CARVALHO \& J.M.F.C. Influência de Rhizopus sp., Aspergillus niger e Aspergillus flavus na deterioração de sementes de algodoeiro armazenadas. Fitopatologia Brasileira 9:555-560. 1984.

LOEFLER, T.M., TEKRONY, D.M. \& EGLI, D.B. The bulk conductivity test as an indicator of soybean seed quality. Journal of Seed Technology 12:37-53. 1988.

LOEFLER, T.N. The bulk conductivity test as an indicator of soybean seed quality. (Tese de Mestrado). Lexington. University of Kentucky. 1981.

LOOMIS, E.L. \& SMITH, O.E. The effect of artificial aging on the concentration of $\mathrm{Ca}, \mathrm{Mn}, \mathrm{K}$ and $\mathrm{Cl}$ in imbibing cabbage seed. Journal of the American Society for Horticultural Science 105:647-650. 1980.

ACHADO, J.C. Tratamento de Sementes no Controle de Doenças. Lavras. LAPS / UFLA / FAEPE. 2000.

McDONALD, D., FIELDING, W.L.\& RUSTON, D.F. Experimental methods with cotton. III-Sulphuric acid treatment of cotton seed and its effect on germination, development and yield. Agricultural Science 37:291-296. 1947.

PAOLINELLI, G.P., BRAGA, S.J. FALLIERI, J. \& SARAIVA, H.A.B. Efeito comparativo de diferentes processos de deslintamento sobre a qualidade de sementes de algodoeiro herbáceo. Informativo ABRATES 5:64. 1995. (edição especial).

PIZZINATO, M.A. Testes de sanidade de sementes de algodão. In: Soave, J. (Ed.) Patologia de Sementes. Campinas. Fundação Cargill. 1987. pp. 331-357.

PIZZINATO, M.A. Relação entre densidade e qualidade de sementes de algodoeiro (Gossypium hirsutum L. var. latifolium Hutch.) e patogenicidade de Fusarium spp. Link ex Fr. (Tese de Doutorado). Piracicaba. ESALQ. 1988.

POWELL, A.A. Cell membranes and seed leachate conductivity relation to the quality of seed for sowing. Journal of Seed Technology 10:81-100. 1986.

REDINGTON, C.B. \& PETERSON, J.L. Influence of environment on Albizzia julibrissin root exudation and exudate effect on Fusarium oxysporum f. sp. perniciosum in soil. Phytopathology 61:812-815. 1971.

SCHROTH, M.N. \& SNYDER, W.C. Effect of host exudates on chlamydospore germination of the bean root rot fungus, Fusarium solani f. phaseoli. Phytopathology 51:389-393. 1960.

SOBREIRA, D.G. Qualidade e detecção de fungos em alguns lotes de sementes de algodão (Gossypium hirsutum L.) produzidas no Estado de Minas Gerais, safra 1985/86 (Tese de Mestrado). Lavras. ESAL. 1988.

TEIXEIRA, H. Colletotrichum gossypii South. em sementes de algodoeiro (Gossypium hirsutum L.): Transmissibilidade e controle. (Tese de Mestrado). Lavras. UFLA. 1995.

WOODSTOCK, L.W. Seed imbibition: a critical period for successful germination. Journal of Seed Technology 12:1-15. 1988. 